\title{
A Method for Producing Graduate Level Scholars in Classical Performance
}

\author{
Natthakan Bunsiri ${ }^{1}$, Surapone Virulrak ${ }^{2}$ \& Akom Sangiemwiboon ${ }^{1}$ \\ ${ }^{1}$ Faculty of Fine and Applied Arts, Mahasarakham University, Khamriang Sub-District, Kantarawichai District, \\ Maha Sarakham Province, Thailand \\ ${ }^{2}$ Surapone Virulrak, 35/160 Noble House Phyathai, Phyathai Road, Ratchathevi, Bangkok, Thailand \\ Correspondence: Natthakan Bunsiri, Faculty of Fine and Applied Arts, Mahasarakham University, Khamriang \\ Sub-District, Kantarawichai District, Maha Sarakham Province 44150, Thailand. E-mail: \\ natthakan.bunsiri@gmail.com
}

Received: July 3, 2013 Accepted: August 20, 2013 Online Published: October 29, 2013

doi:10.5539/ass.v9n15p181 URL: http://dx.doi.org/ass.v9n15p181

\begin{abstract}
The development of classical performance studies at university level is a major development in the field of fine and applied arts studies in Thailand as a whole. This qualitative study used in-depth interviews and discussions with experts and policy-makers in the field, as well as personal observations to identify a method for producing graduate level scholars in Thai classical performance. The study found that Rajabhat Universities first offered classical performance studies on the graduate level by incorporating it as a part of their arts studies program. Later these studies were given their own division within the department of arts, with majors offered at both the masters and doctoral level. This was made possible by integrating traditional performance arts studies with other disciplines such as folk-studies, environmental research, and global trends. In addition to focusing on student execution of traditional dance, real-world performance experience and development of creativity as artists, these new programs made inter-disciplinary studies an essential part of becoming an expert in classical performance. This research concludes that in order to create scholars of classical performance on the graduate level with the capacity to improve classical performance study programs in state institutions throughout the country, well-rounded programs must be developed, leading to the creation of scholars able to preserve classical Thai performance arts long into the future.
\end{abstract}

Keywords: graduate, classical performance, dance, Thailand, curriculum, development

\section{Introduction}

Adaptations to currents of globalization that happened rapidly during the past decades have forced the global population to confront a variety of different changes in complex structures that are increasingly linked. Education is the most important thing that has been influenced by these rapid changes. This is visible in the creation of organizations with responsibility for the development of quantity and quality in different areas of education. These organizations are instructed to create standards that meet requirements of the national economic and education development plans, as well as the trends and conditions of competitions that are ever more important in Thai society. Educational institutions, especially governmental institutes in Thailand, are places that create important knowledge and human resources for the society. These institutes have four important missions, which are: a) teaching and producing graduate level scholars; b) research and creative work; c) academic service; d) preservation and support of art culture.

Modern organization of education in classical performance is a sign of advanced progress in Thailand and covers all twelve levels of education according to the local curriculum from the year 2001. The classical performance subject is also taught across the country in performance colleges and graduate institutions for the development of art. The field of performance art in higher education institutions is progressing rapidly.

Problems in the production of graduate level scholars come from a number of factors, which begin from the fact that the subject is only familiar among teachers of the subject and interested people. Nowadays, the curriculum is widespread to give people an opportunity to receive its knowledge and increase participation. This refers to inclusion of outsiders in the curriculum design and process, including experts, artists, local philosophers, leaders 
and those with participatory interest in the curriculum. This creates increased awareness among the community and raises the importance of the curriculum. Aside from this, there is no consistency in improvement of the curriculum with regards performance according to clear and certain time proposals. This can be seen from the variety of curriculums in various education institutes that organize learning and teaching according to the same curriculum. There are also long time-frames with no improvements or adaptations to subjects so that they are up-to-date and meet the needs of the market. For these reasons, there are weaknesses in current curriculum development for the teaching of classical performance arts, which reflect the vision of the developers and their insufficient level of attention to developing and improving the curriculum. Furthermore, there is no integration of the curriculum to provide complete subject knowledge for the students, rather focusing on single branches of study. Additionally, there are internal factors from the Ministry of Education policies that relate to the provision of regional education opportunities, which have caused the regional education institutions to double their enrolment figures. Many curriculums have increased their intake rapidly, which has caused the management of the curriculum to be unclear in its objectives and methods of graduation. This has in turn created problems with overlapping curriculums in the same institutions and problems linked to subject details, both theoretical and practical, that do not correspond to one another. There are also problems with a lack of teachers and suitability of teachers, which results in a lack of quality education and development of curriculum. The methods for production of graduate level scholars do not, therefore, match the objectives.

Government universities began to teach according to undergraduate curriculums for classical performance art in the art department and evolved their own subject courses for classical performance art. Thirty-six institutions teach the subject as a major or minor subject at bachelor level. The subject was first taught as a stand-alone bachelor course at Chulalongkorn University in 1988 and spread to seven universities by 1997. There was development of the curriculum, which enabled the opening of a fine arts department for master and doctoral students, in 1989 and 1999 respectively. The branch of Thai classical performance was created in the classical performance subject of the Fine Arts Department at Chulalongkorn University. This shows the progress of the classical performance subject in both the number of educational institutions and the level of curriculum (Virulrak, 2006, pp.88-89).

Suan Sunanta Rajabhat University was the first government educational institute to offer a higher vocational diploma in classical performance in the year 1972, according to the policy of producing primary and secondary school teachers. From this starting point, other universities opened courses according to their readiness. In 1976, the curriculum was improved to a degree classification. In 1984, the universities opened a curriculum for Graduate Fine Arts in classical dance and performing arts at diploma and bachelor levels. The curriculum for the study of graduate education in classical performance was opened in twenty-four government universities and the curriculum for fine arts was opened in two institutes (Virulrak, 2006, pp.94-95). There were two objectives for the opening of these courses: a) a graduate study curriculum to produce classical performance teachers for primary and secondary education; $b$ ) to produce professional performers.

Graduate programs in classical performing arts came about through continual educational competition and, until now, over five thousand graduates have qualified from the system. However, nowadays there is a continually increasing demand for classical performance graduates. Over eighty percent of graduates go into related occupations. The academic system and its policies have been rapidly developed by the professional quarter, which has been caused by the government education reform policies to develop Thai nationals to have increased knowledge and expertise and to increase the quality of national education.

The organizations with a role in developing and enhancing the progress of graduate education include the Office of the Higher Education Commission and the Office for National Education Standards and Quality Assessment (ONESQA). The main responsibilities of these organizations are in efficient and productive curriculum management and quality production of graduates, as well as modernization of the curriculum and management of education equality. This enables the management of classical performance education to use high-quality procedures.

Nowadays there are requirements for the development of knowledge and skill that is to be used in everyday life and a variety of occupations. The creation of fundamental specifications and curriculum models in higher education helps the education institutes to adapt their teaching methods and efficiently organize education according to the individual institutional ability (Wirawatnanon, 2000). In this way the guarantees of quality education are things that the universities, educational institutes, academic departments or faculties already implement. The selection process among students regarding their choice of institution, faculty or subject, is the first step that reveals the popularity and reputation of the institution or faculty (Jamraman, 2000). In the past, the guarantees of education created an overall picture and were used to indicate the quality, quality assessment, 
quality control and guarantee of quality (Wiriyawechagoon, 1998).

There has been research to develop and indicate the quality of each level of education, from primary to higher. However, there is minimal research to study the development of education management methods, especially regarding the curriculum. There has been no research to reveal or indicate the characteristics of graduate production in classical performance. For these reasons, the research team realized that the results from investigation of a method for producing graduate level scholars in classical performance would provide important new knowledge.

\section{Research Objectives}

This research aimed to identify a method for producing graduate level scholars in classical performance that could be used for the development of education management in classical performance for higher education in government institutes. A summary of the research concepts used in this research can be seen in figure 1 below.

\begin{tabular}{|l|l|l|}
\hline $\begin{array}{l}\text { Learning and Teaching Process } \\
\text { - Definition and meaning } \\
\text { - } \quad \text { Learning process related to cognitive work } \\
\text { - Creative thinking } \\
\text { - Integrated learning and teaching process } \\
\text { - Analytical chapters for the integrated } \\
\text { teaching of arts }\end{array}$ & \\
\hline $\begin{array}{l}\text { Development of curriculum for higher } \\
\text { education } \\
\text { Definition and meaning of development } \\
\text { General conditions and problems } \\
\text { Curriculum development policies }\end{array}$ & $\begin{array}{l}\text { Arts Education } \\
\text { Planned arts education } \\
\text { Arts education in mixed wisdom } \\
\text { Arts education in local Thai wisdom } \\
\text { Contemporary arts education } \\
\text { Arts education in special abilities }\end{array}$ \\
\hline
\end{tabular}

Figure 1. Research concept framework

\section{Research Methodology}

\subsection{Research Area and Sample}

This qualitative research selected a sample population of ten higher-education institutes throughout Thailand offering a continual classical performance education program over the last ten years. The institutes selected from Northern Thailand included Naresuan University and Chiang Mai University. The institutes selected from Central Thailand included Chulalongkorn University, Srinakharinwirot University, Suan Sunanta Rajabhat University and Bunditpatanasilpa Institute. The institutes selected from Northeastern Thailand included Mahasarakham University and Surin Rajabhat University. The institutes selected from Southern Thailand included Thaksin University and Phuket Rajabhat University. This research was conducted over two academic years from 2010 to 2012 .

\subsection{Methodology and Research Tools}

The first stage of the research was the analysis of conditions and background of classical performance education in Thailand by using related documentary study. The second stage of research was the analysis procedure, which included five steps. The first step was study of development concepts for education standards. The second step was study of data related to classical performance education for bachelor students in the ten universities. The third step was the study of higher education qualification standards for classical performance. The fourth step was the gathering of opinion from three groups: experts in checking research tools; personnel related to education management; experts in classical performance. Tools used for this research were in-depth interview, focus-group discussion and observation. There were two objectives to the fourth step, which were to gather opinion regarding the ability expectations of successful classical performance graduates and to gather opinion on the components of classical performance education management. The fifth step was analysis, conclusion, adaptation and correction. The third stage of the research was to present a complete model and report the research results. 


\subsection{Methodological Approach}

This study arose from a close consideration of the various ways in which classical performance is taught and thought about in Thailand, with a focus on how scholars in classical performance can be created on the graduate level utilizing an interdisciplinary approach to their education. The study is based upon various theories of education and knowledge acquisition; besides the Buddhist model known as 'Itthipajyta' or 'natural law'. The research employed Ken Wilber's (1993) 'integral theory' in combination with research conducted at ten institutions of higher education with degree programs in classical performance throughout Thailand. This included a wide-ranging survey of teaching materials, in-depth interviews with experts and policy-makers in the field, and personal observations. The data acquired was later taken and analyzed according to Wiroon Tungcharoen's (2010) theories of arts education. The result is this descriptive analysis.

\section{Research Results}

\subsection{Current Conditions of Education Management in Classical Performance for Higher Education in Thailand}

The management of classical performance education in Thailand includes all levels of education in the arts department following the 2001 regional curriculum, which is divided into four key-stages. The classical performance subject is taught from the first level of primary education until the final year of secondary education. Aside from this, it is also taught in performance colleges and arts development institutions across the country. A primary objective of these educational institutions is to harmonize the education management between secondary and higher education by planning classical performance education. Aside from this, management of higher classical performance education has rapidly advanced, especially in government universities.

From survey of classical performance education management at the bachelor level in the ten higher education institutions selected by the research with classical performance offered as a major subject between 2010 and 2012 , it was found that the curriculums had one of two characteristics. These were professional development for performers and professional development for teachers.

The management of higher education curriculums in Thai classical performance is governed by standards set by the Bureau of Standards and Evaluation. The course content and details are the responsibility of the Ministry of Education. Education in the Thai classical performance subject will cover meanings, regions, history, theories and models of Thai classical dance and other internationally important classical dances; background and dance postures of regional indigenous dances; demonstrations and training; standards of dance; production of dances and important performances; higher performance training; planning, preparation and management of classical dance; choreography and creation of classical dance and contemporary dance; background design and creation, costume design; make-up; lighting management; dance steps; plot; and classical dance research.

The researchers identified four focuses for the curriculums, which were curriculums that emphasize research or creation; curriculums that emphasize region; curriculums that emphasize production; and curriculums that emphasize conservation. The necessary subject knowledge includes dramatic literature, production skills, classical performance historiography, artistic components, administrative management of performance art and presentation of performance art. Teaching must be an integrated, student-centered process. The methods of teaching classical performance from the past to the present have been student-centered, using an experience-based teaching approach, teaching with the artist as a model and teaching by blended learning. Methods of evaluating study results have been various and the institutes are entrusted by the Ministry of Education to manage student success, failure and development themselves.

\subsection{Development of a Method for Producing Graduate Scholars in Classical Performance}

Development of concepts and creation of graduate characteristics was based on results from document study and field research, including interviews and discussions with experts, academics, curriculum heads and related personnel. The following nine characteristics were identified: science and skill-possession of deep knowledge in the science and skill of classical performance; uniqueness and universality-possession of a Thai identity and understanding of international ideas; respect and responsibility-possession of clear professional ethics and respect of elders; appreciation and attitude-possession of a good attitude and faith in the professionalism of classical dance; professionalism and potential-possession of potential and desire to be professional in creation of work; original and optimum situation-possession of creative and original ideas and imagination; nature and nationality-possession of an understanding of nature and the requirements of a good citizen; energy and evaluation-possession of energy to self-develop and improve work and ability to evaluate; heart and harmony-possession of aesthetic experience and the ability to control moods and exercise caution. The links between each characteristic is displayed in the following figure (figure 2). 


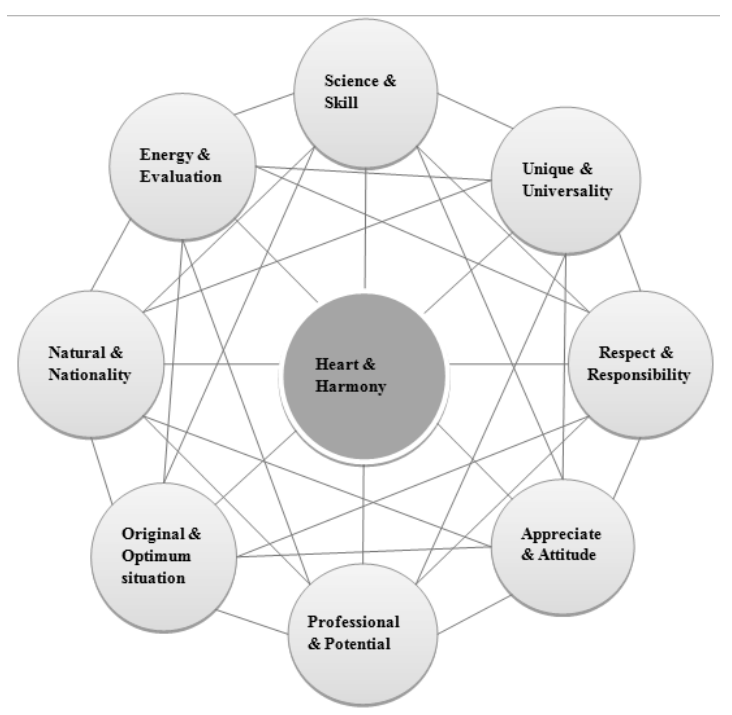

Figure 2. Links between the nine characteristics of a classical performance graduate scholar

\subsubsection{Conditions of Learning}

Regarding the conditions of learning for bachelor degree study, there must be a general education curriculum and professional education curriculum that promote adequate knowledge and understanding among students. For the professional components, there must be a large enough number of subject options for the individual student to creatively develop themselves and subjects must be up-to-date with academic, social and global changes. There must be a learning process for students to independently search for knowledge, independently create knowledge development, work training and practice and adapt the concepts and practices learned for use in society. There must be organization of activities and processes for students to analyze, synthesize, evaluate and create. At the same time, there must be links between learning, teaching and the organization of activities to provide opportunities for students to participate in and manage programs with others and become involved in activities for development of themselves, their ethics and their sense of social responsibility.

The prominent features of the model characteristics for graduates in Thai classical performance are ability to work, ability to work with others and possession of the power to create work. These characteristics should be visible in all graduates when entering the world of work and they must develop themselves to seek knowledge and create new knowledge suitable for their work. Aside from this, in their work and life as part of choreographic society, the graduates must know how to analyze in order to understand, be up-to-date and not be misled by their environment. The new generation of choreographers must be innovative in classical performing science, which emphasizes beauty and form. For this reason, the graduates must know about aesthetics, in terms of knowledge and understanding of themselves and others. In this way, the graduates champion the maintenance of Thai art culture, with awareness of the essence of Thai identity and appropriate incorporation of international changes. The graduates must take responsibility for themselves, society and ethics and hold good values. Qualified artists with these characteristics will stand out.

From these characteristics it is possible to identify four further levels of scholar, which are foundation, developed, advanced and excellent. The characteristics required for the achievement of these levels are shown in the following table (Table 1). 
Table 1. The qualities of four levels of graduate scholar in Thai classical performance

\begin{tabular}{|c|c|c|c|c|}
\hline Potential & Foundation & Development & $\underline{\text { Advancement }}$ & Excellence \\
\hline Knowledge & $\begin{array}{l}\text { Possession of } \\
\text { knowledge about } \\
\text { the science of } \\
\text { classical } \\
\text { performance and } \\
\text { related subjects }\end{array}$ & $\begin{array}{l}\text { Possession of deep } \\
\text { knowledge and } \\
\text { ability to } \\
\text { continually search } \\
\text { for knowledge }\end{array}$ & $\begin{array}{l}\text { Possession of } \\
\text { knowledge in art } \\
\text { that relates to the } \\
\text { contexts of society, } \\
\text { local wisdom and } \\
\text { culture }\end{array}$ & $\begin{array}{l}\text { Ability to gain } \\
\text { access to } \\
\text { knowledge and } \\
\text { create new bodies } \\
\text { of knowledge }\end{array}$ \\
\hline Thought & \begin{tabular}{lr}
\multicolumn{2}{l}{ Possession } \\
ability to \\
about cause and \\
effect
\end{tabular} & $\begin{array}{l}\text { Possession } \\
\text { ability to } \text { of } \\
\text { analytically } \\
\text { creatively, } \\
\text { according } \\
\text { modern trends }\end{array}$ & $\begin{array}{l}\text { Possession of } \\
\text { ability to integrate } \\
\text { thought and } \\
\text { forward-think }\end{array}$ & $\begin{array}{lr}\text { Possession } & \text { of } \\
\text { ability to think } \\
\text { systematically and } \\
\text { collectively } \\
\text { evaluate }\end{array}$ \\
\hline Production Skill & $\begin{array}{l}\text { Possession of } \\
\text { ability to produce } \\
\text { work according to } \\
\text { professional } \\
\text { standards }\end{array}$ & $\begin{array}{l}\text { Possession of } \\
\text { ability to adapt and } \\
\text { develop work so } \\
\text { that it is accurate } \\
\text { and find new } \\
\text { methods }\end{array}$ & $\begin{array}{l}\text { Possession of } \\
\text { production skill and } \\
\text { expertise with the } \\
\text { ability to create new } \\
\text { work independently }\end{array}$ & $\begin{array}{l}\text { Possession of } \\
\text { ability to create new } \\
\text { things and use } \\
\text { unique individual } \\
\text { methods }\end{array}$ \\
\hline $\begin{array}{l}\text { Communication } \\
\text { Skill and } \\
\text { Technology }\end{array}$ & $\begin{array}{l}\text { Possession of the } \\
\text { ability to } \\
\text { communicate by } \\
\text { speaking, listening, } \\
\text { reading and writing } \\
\text { and use technology }\end{array}$ & $\begin{array}{l}\text { Possession of the } \\
\text { ability to } \\
\text { communicate and } \\
\text { select technology in } \\
\text { order to search for } \\
\text { and present suitable } \\
\text { work results }\end{array}$ & 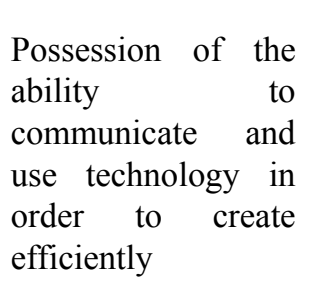 & $\begin{array}{l}\text { Possession of the } \\
\text { ability to apply } \\
\text { communication and } \\
\text { technology for use } \\
\text { in the profession }\end{array}$ \\
\hline Ethics & $\begin{array}{l}\text { Possession of } \\
\text { discipline, } \\
\text { responsibility and } \\
\text { integrity, as well as } \\
\text { professional culture } \\
\text { and morality }\end{array}$ & $\begin{array}{l}\text { A good role-model } \\
\text { who understands } \\
\text { themselves, others } \\
\text { and the world }\end{array}$ & $\begin{array}{l}\text { Promotes and } \\
\text { identifies society so } \\
\text { that it becomes } \\
\text { aware of ethics }\end{array}$ & $\begin{array}{l}\text { Dedicated } \\
\text { cooperation } \\
\text { public } \\
\text { consciousness }\end{array}$ \\
\hline Values & $\begin{array}{l}\text { Possession of } \\
\text { devotion and faith } \\
\text { in classical } \\
\text { performance work }\end{array}$ & $\begin{array}{l}\text { Possession of } \\
\text { aesthetic sense in } \\
\text { accepting and } \\
\text { understanding mood } \\
\text { of themselves and } \\
\text { others }\end{array}$ & $\begin{array}{l}\text { Possession } \\
\text { energy to propel } \\
\text { personal } \\
\text { development, } \\
\text { development of } \\
\text { work and evaluation }\end{array}$ & $\begin{array}{l}\text { Possession } \\
\text { expectations } \\
\text { unique } \\
\text { creation }\end{array}$ \\
\hline
\end{tabular}

Classical performance education must produce graduate scholars to enter civic education by giving the teachers a role to empower their students and make them reliable people in civic education. It was found impossible for a graduate scholar to be lacking in any one of the nine given characteristics. The founding concepts of the teaching methods must enable the students to search for knowledge and naturally develop the ability of the student according to their own potential. Therefore, there should be support of production according to real work conditions by connecting aspects of the education with the society. This will enable the students to learn about many different situations inside and outside of the classroom. This also trains the students to think analytically and creatively throughout their lives, as well as integrate and evaluate different things (Figure 3). 


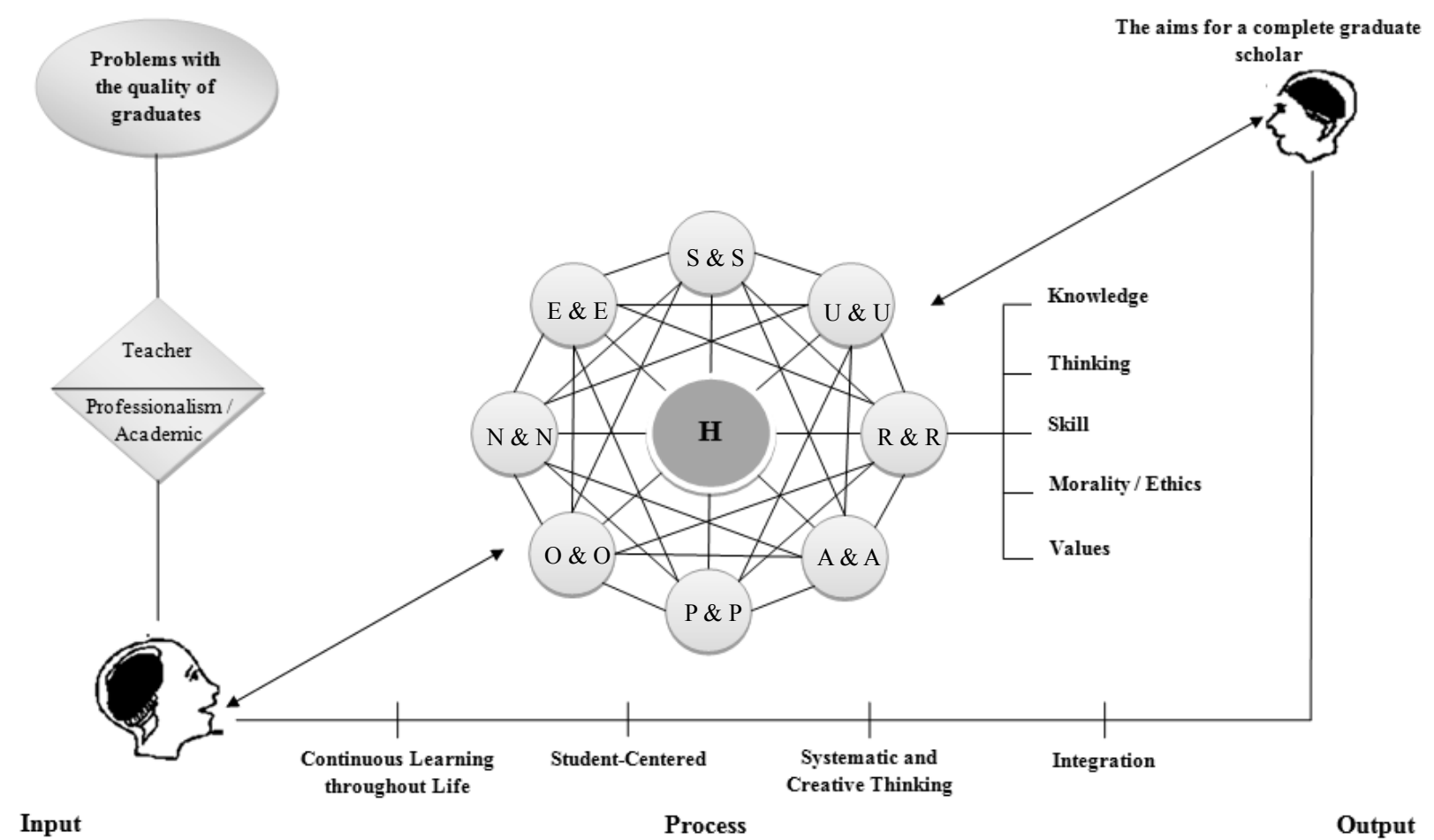

Figure 3. Production of graduate scholars in classical performance at bachelor level

\section{Discussion}

This research has taken a number of definitions of the word development. Development means the 'slight and subtle changes over a number of different steps to move, grow and improve a thing to be more appropriate' (Priyakorn, 1995). It is also considered by the Royal Institute as 'progression or adaptation for further progression in a better way' (Royal Institute, 1995). Additionally, development is the 'change of something so that it is better and more advanced' (Ponsri, 2004). With curriculum set to mean the running sequence of courses or learning experience, Saylor and Alexander consider curriculum development to mean the improvement of the current curriculum or the introduction of a new curriculum where there was no previous curriculum in place. This may include the creation of study material for students (Pupan, 2003).

The concepts of producing graduate scholars in classical performance at bachelor level may have the following steps: a) design of production method, which has three areas of consideration-the learning aims, the method for assessing achievement of learning aims and development so that students may meet the learning aims; b) the origin of the learning aims; c) the method of quality assessment-to what extent the student has achieved the learning aims, to what extent the student possesses expected characteristics, the presence of work that shows the skill and ability of the student according to the learning aims, and the knowledge, ability and behavior of the student; d) the methods to be used for developing the student so that they meet the learning aims.

The realization that the characteristics of a graduate scholar in classical performance are all-encompassing and that one aspect may not be lacking corresponds to the system of holistic thinking is based on the hypothesis that the world and its countries are like a living organism with its body parts. Every part is reliant upon the other in a structure which influences behaviors. Changes to the structure are not unique and independent developments but are a continuous procedure to meet the needs of the organism. Thus, the organism and its parts must be treated as a single entity rather than a collection of sub-organs (Smuts, 1927). To create scholars of classical performance on the graduate level with the capacity to improve classical performance studies programs in state institutions throughout the country, no single facet of the programs can be improved. Rather, improvements must be made on an inter-disciplinary level, especially by developing productive connections with fields not currently taught. In this way, well-rounded programs can be developed, leading to the creation of scholars able to preserve classical Thai performance arts long into the future.

For the optimum production of graduate scholars of classical performance, the teachers must be instructors and adopt the role of advisors and helpers rather than formal educators. This will enable the student to develop their own styles and concepts independently, which they can then use in society. Therefore, it is necessary for the instructors to teach the students in skill rather than knowledge because nowadays all students have access and are 
able to find required knowledge. In this way, when there is added competition from the opening of the ASEAN community, Thai artists will have the required expertise and tools to contend on a level with those professionals from other countries.

Therefore, from the essence of reforms and social and economic currents, the learning society of the modern era classical performance teachers must have a more complicated role. The teachers must possess knowledge and experience and be up-to-date. They must have a wide and far-reaching vision, which should be evident in the management of their teaching steps. The development of education must be student-centered. Future teachers must meet the quality standards of professional teachers accepted by society. Teachers must also be prepared for modern society and the changes it will bring.

This increased competition from ASEAN and further globalization will raise the expectations placed upon graduate scholars of classical performance. Current graduates possess insufficient knowledge, which stems from a number of factors. The most important factor is that the world of knowledge has changed from the past, due to the economy and industry. Graduate scholars must continue to accumulate knowledge and experience after their graduation, so to remain in touch with modern changes to the economy and society, as well as new technology. This is part of the conservation and inheritance process.

There remain a number of reasons for problems with the knowledge and ability of a majority of artists. The most important factor is changing of global knowledge, which has caused business and industry to adjust rapidly to compete in the market. The education sector has been unable to keep up with business and industry so there is now little or no link. This means that graduates must inherit additional knowledge before they are able to begin their work. The graduates must also possess the ability to continually receive information, knowledge and modern technology throughout their working lives. Students must have the desired characteristics and ability to use new technology and communicate in foreign languages.

The study of classical performance must be conducted in a community of practice (CoP) to achieve the most successful results. This is based on the model of Jean Lave and Etienne Wenger (1991) using knowledge management and the stimulus of learning as inspiration and motivation. The researchers thus identified five necessary traits for students of classical performance in Thailand: a) intelligence; b) the ability to find knowledge for themselves (they must be a learning person); c) deep feelings towards theory and practice; d) ability to use technology and innovations; e) existence as part of a learning society. With these traits and the characteristics of a desirable classic performance graduate instilled by dedicated modern instructors, using a developed curriculum in tune with modern society and economy, future graduate scholars of classical performance in Thailand will be able to cope with the new demands of the ASEAN community and globalized society.

\section{References}

Jamraman, U. (2000). Quality guarantees at the higher education level. Bangkok: Funny Publishing.

Lave, J., \& Wenger, E. (1991). Situated Learning: Legitimate Peripheral Participation. Cambridge: Cambridge University Press. http://dx.doi.org/10.1017/CBO9780511815355

Ponsri, S. (2004). Theories and principles of community development. Bangkok: Odeon Store.

Priyakorn, P. (1995). Development theories and concepts in administrative development. Bangkok: Samjaroenpanit.

Pupan, S. (2003). Founding concepts of curriculum creation and development in the age of reform of Thai education. Chiang Mai: The Chiang Mai Knowledge Center.

Royal Institute. (1995). Royal Institute Dictionary (5th ed.). Bangkok: Aksornjaroentat.

Smuts, J. (1927). Holism and Evolution. London: McMillan and Co Limited.

Tungcharoen, W. (2010). Artistic Vision. Bangkok: Srinakharinwirot University Publishing Center.

Virulrak, S. (2006). Classical dance of Rama IX. Bangkok: Chulalongkorn University Press.

Wilber, K. (1993). The Spectrum of Consciousness. New York: Quest Books.

Wirawatanon, W. (2000). Foundation and model of curriculum development required by graduate education. Bangkok: Ministry of University Affairs.

Wiriyawechagoon, A. (1998). Quality academic guarantees in Thai universities. Bangkok, Mahidol University Press.

\section{Copyrights}

Copyright for this article is retained by the author(s), with first publication rights granted to the journal.

This is an open-access article distributed under the terms and conditions of the Creative Commons Attribution license (http://creativecommons.org/licenses/by/3.0/). 